\title{
Perancangan Buku Visual Batik Gedog sebagai Media Pelestarian Motif Batik Tuban
}

\author{
Dianita Rahma Maulida dan Senja Aprela Agustin \\ Departemen Desain Produk, Institut Teknologi Sepuluh Nopember(ITS) \\ e-mail: senja@kotasis.com
}

\begin{abstract}
Abstrak - Batik Gedog memiliki ciri khas motif dan warna yang berbeda dari batik daerah. Warna batiknya didominasi biru dan merah. Saat ini motif lama batik Gedog kurang populer dibandingkan motif pengembangan yang mengikuti selera pasar, beberapa motif pun sudah tidak pernah diproduksi serta tidak ada data pasti mengenai jumlah motif batik yang ada. Belum ada media yang mendokumentasikan berbagai motif Batik Gedog. Pendokumentasian motif Batik Gedog bertujuan untuk menyimpan motif yang ada agar tidak punah dan dapat dipelajari serta dibuat kembali oleh generasi berikutnya. Perancangan buku visual Batik Gedog Tuban ini menggunakan beberapa metode. Diantaranya adalah riset etnografi untuk melihat situasi pada desa Kerek, depth interview kepada narasumber yang berkaitan dengan Batik Gedog yaitu pengrajin sekaligus pelestari Batik Gedog, kolektor Batik Gedog serta dinas perindustrian dan perdagangan kabupaten Tuban untuk mengetahui beberapa pandangan mengenai Batik Gedog serta literatur terkait. Data yang ada kemudian dikomparasikan dengan kompetitor untuk mendapat konten buku yang sesuai. Hasil dari perancangan ini adalah buku visual motif Batik Gedog Tuban yang membahas motif serta makna dibaliknya, kehidupan masyarakat yang menggunakan batik, sejarah, ciri-ciri, perbedaan, fungsi hingga perkembangan Batik Gedog Tuban. Melalui perancangan buku visual Batik Gedog Tuban ini diharapkan dapat melestarikan motif yang ada sehingga bermanfaat bagi kolektor batik dan pengrajin, serta untuk memperkenalkan Batik Gedog kepada masyarakat yang lebih luas. Buku ini dilengkapi dengan elemen visual berupa fotografi serta ilustrasi untuk merekonstruksi penggunaan batik gedog di masa lalu.
\end{abstract}

Kata Kunci-Batik Gedog, Buku Visual, Motif.

\section{PENDAHULUAN}

K ABUPATEN Tuban adalah satu dari sembilan kabupaten di Jawa Timur yang memiliki batik klasik. Keunikan Batik Gedog dipengaruhi oleh akulturasi tiga budaya yang ada di wilayah tersebut yaitu Jawa (Majapahit), Islam dan Cina karena Tuban merupakan kota pesisir dan menjadi pusat perdagangan yang besar sehingga orang-orang datang ke Tuban.

Pembuatan Batik Gedog dilakukan masyarakatnya dari awal yaitu menanam kapas sebagai bahan kain hingga akhir yaitu pewarnaan. Semua bahan yang di gunakan dalam proses pembuatan Batik Gedog ditanam oleh masyarakat Kerek di pekarangan rumah. Batik Tuban digunakan pada upacaraupacara tradisional seperti sedekah bumi, pernikahan dan pemakaman, terdapat doa yang dipanjatkan dalam motif yang dipakai. Budaya yang tumbuh memiliki pengaruh terhadap motif yang dibuat, misalnya motif Kijing Miring yang di pengaruhi Islam, Lokcan yang di pengaruhi budaya Cina, dan Panji Ori yang di pengaruhi budaya Jawa.

Saat ini, pengrajin lebih banyak memproduksi batik motif pengembangan untuk memenuhi selera pasar yang baik untuk penjualan karena meningkatkan popularitas gedog, namun di

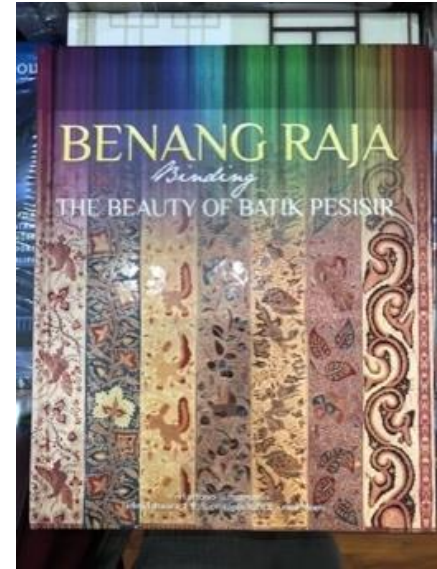

Gambar 1. Buku Batik Benang Raja.

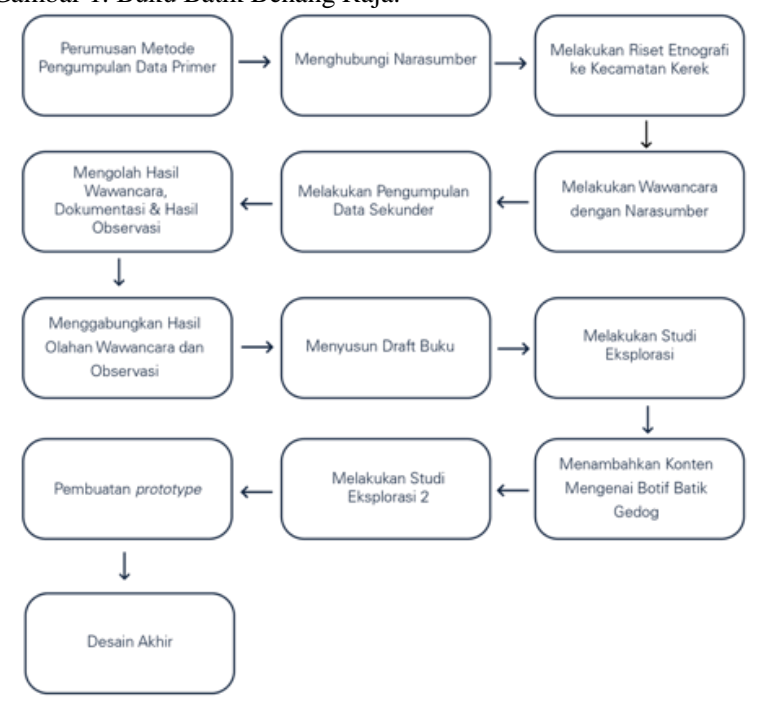

Gambar 2. Alur Perancangan.

sisi lain hal ini berpengaruh pada motif-motif tradisional dari Batik Gedog. Beberapa motif terancam punah dan tidak di kenali oleh pengrajin sendiri[1]. Selain itu belum ada catatan maupun dokumentasi yang baik agar dapat dipelajari oleh generasi berikutnya.

\section{A. Identifikasi Masalah}

1. Beberapa motif tradisional Batik Gedog sudah jarang di produksi kembali.

2. Kurangnya pengetahuan masyarakat serta pengrajin sendiri terhadap jenis-jenis motif serta pemahaman makna dari motif Batik Gedog.

3. Motif pengembangan yang saat ini lebih digemari oleh masyarakat.

\section{B. Rumusan Masalah}

Bagaimana merancang sebuah media yang berisikan ragam motif Batik Gedog Tuban sebagai salah satu upaya pelestarian batik? 


\section{Batasan Masalah}

1. Pada perancangan ini penulis akan menyelesaikan permasalahan yang berkaitan dengan pelestarian Batik Gedog Tuban melalui media buku visual.

2. Perancangan ini hanya membahas konten yang berkaitan dengan motif Batik Gedog Tuban yaitu sejarah, teknik pembuatan dan jenis-jenis motif serta makna dari batik.

\section{Maksud dan Tujuan}

1) Manfaat Akademik

Sebagai buku rujukan untuk mengetahui berbagai motif dan makna Batik Gedog Tuban.

\section{2) Manfaat Praktis}

- Membantu Dinas Perindustrian dan Perdagangan Kabupaten Tuban dalam upaya pendokumentasian motif Batik Gedog Tuban kepada masyarakat luas.

- Menambah pengetahuan tentang salah satu kebudayaan di Indonesia, khususnya Jawa Timur.

\section{STUDI PUSTAKA}

\section{A. Landasan Teori}

\section{1) Batik Gedog Tuban}

Teori ini mencakup sejarah Batik Gedog Tuban, mulai dari proses pembuatan hingga ragam motif batik. Seluruh informasi ini di dapat dari berbagai sumber literatur baik cetak maupun digital terkait batik gedog dan hasil depth interview terhadap stakeholder. Perbedaan Batik Gedog dengan batik lain adalah penggunaan bahan kain Tenun Gedog. Jenis tenun yang digunakan untuk batik yaitu berwarna putih polos maupun yang telah berwarna. Hal ini menambah tingkat kesulitan saat akan di batik karena membutuhkan ketelitian yang tinggi agar motif tetap simetris. Batik Gedog memiliki beberapa motif khas yang masih populer hingga saat ini, diantaranya yaitu motif lokcan, krompol, ganggeng, gringsing, panji ori, dan lain-lain[1].

\section{2) Perancangan Desain}

Teori mengenai perancangan desain buku visual terdiri dari berbagai elemen yang ada pada sebuah buku. Struktur buku umunya dibagi menjadi tiga yaitu bagian depan, berisi cover yang menjadi 'muka buku'dan memiliki penekanan yang cukup besar serta halaman-halaman pembuka seperti daftar isi dan kata pengantar. Kemudian bagian isi buku terbagi menjadi bab-bab sesuai pengelompokkan konten. Dan terakhir adalah halaman penutup. Grid merupakan hal yang perlu diperhatikan karena akan sangat berpengaruh pada kenyamanan pembaca buku[2]. Dalam sebuah grid terdapat hierarki tata letak buku yang berisi judul, subjudul, deck, pull quote, bodytext, caption, kickers, header \& footer[3]. Masing-masing komponen memiliki peranannya dalam memberikan informasi.

\section{3) Fotografi}

Fotografi adalah sebuah proses dalam memproduksi gambar dengan menggunakan aksi radiasi terutama cahaya pada permukaan yang sensitif (seperti film atau sensor optik). Fotografi terbagi menjadi beberapa kategori, diantaranya adalah: foto deskriptif, foto explanatory, foto interpretasi, dan foto estetik.

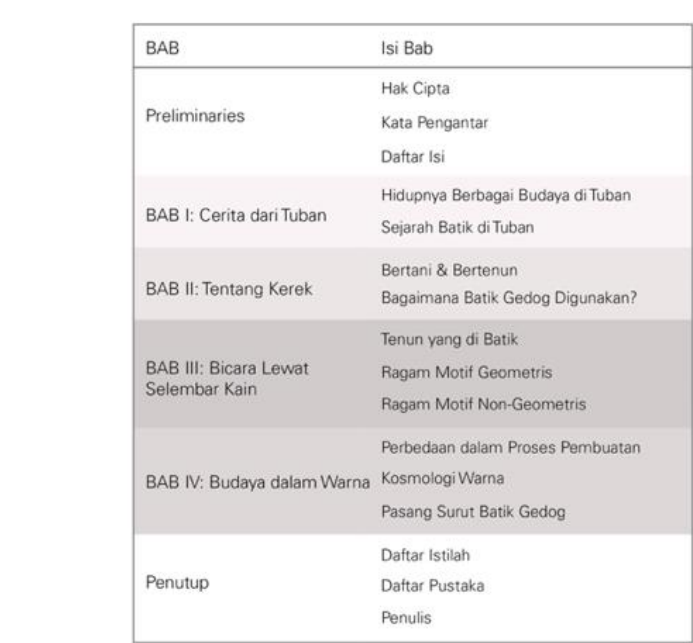

Gambar 3. Kerangka Buku.

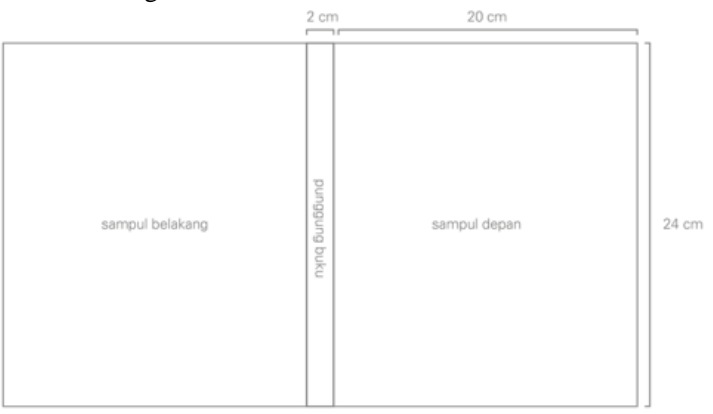

Gambar 4. Dimensi Buku.

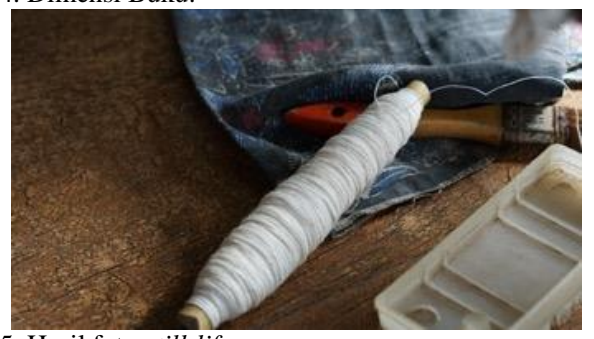

Gambar 5. Hasil foto still-life.

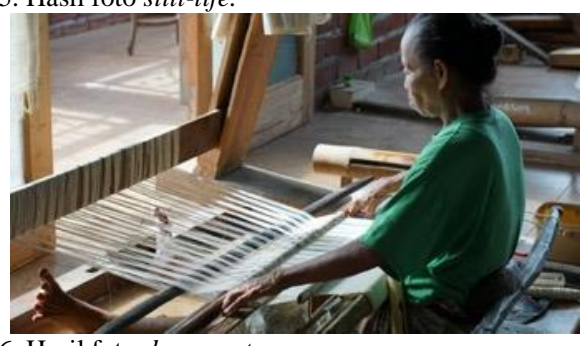

Gambar 6. Hasil foto documentary

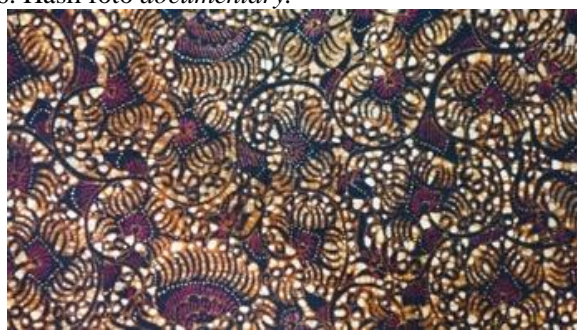

Gambar 7. Hasil foto table-top.

\section{B. Studi Eksisting}

1) Studi Komparator

Buku Batik Benang Raja membahas banyak aspek dari sebuah batik. Mulai dari awal mula sejarah batik, membahas proses pembuatan batik serta naik turun produksi batik. 
Konten utama dari buku ini adalah motif, dengan menampilkan banyak sekali ragam motif beserta variasinya. Satu jenis motif ditampilkan dalam beberapa variasi warna dan penggambaran.

Anatomi dari selembar kain batik pun dibahas dengan detail pada tiap bagian, misalkan bagian papan dan bogemannya.

Melalui motif yang ada dijelaskan pula kegunaan batik sebagai media dalam menceritakan berbagi peristiwa sejarah asli Indonesia hingga kisah dongeng dari luar negeri yaitu Cinderella.

Hal yang dapat diaplikasikan pada buku peneliti yaitu penjelasan yang detail pada tiap motif beserta penjelasan anatomi batik yang di jabarkan. Hasil fotogafi pada buku ini menunjukkan selembar kain secara menyeluruh dan sempurna karena tidak ada lipatan kain yang terlihat atau tidak rata seperti pada Gambar 1 .

\section{METODOLOGI PERANCANGAN}

Alur perancangan pada penelitian ini dapat dilihat pada Gambar 2.

\section{A. Segmentasi Pemasaran}

\section{1) Demografis}

Target audiens buku visual ini universal untuk pria dan wanita dengan rentan usia 30 hingga 50 tahun. Penentuan ini berdasarkan pada usia rata-rata orang-orang yang tergabung pada komunitas batik. Buku visual umumnya tidak dijual dengan harga yang murah, oleh karena itu kemungkinan besar pembeli buku adalah budayawan atau penggemar dan pengoleksi batik.

2) Psikografis

- Memiliki minat terhadap kebudayaan dan kain tradisional khususnya Batik Gedog Tuban.

- Suka membaca atau mengkoleksi buku.

- Bergelut dalam dunia desain fashion.

- Tergabung dalam komunitas

\section{B. Metode Kualtitatif}

\section{1) Riset Etnografi}

Riset etnografi adalah strategi riset yang dibuat oleh antropolog yang berfokus pada hubungan perilaku manusia dengan budaya. Penentuan subjek penelitian dapat dilakukan berdasarkan wilayah geografis, kesukaan, usia atau pun berbagai varietas lainnya. Penelitian dilakukan dengan melakukan riset terhadap subjek, dan kemudian bergabung dalam kegiatan kelompok tertentu untuk mempelajari keseharian dan pola hidup dan interaksi kelompok. Walaupun dilakukan secara objektif, penelitian ini memiliki unsur subjektifitas peneliti. Gabungan antara foto riset observasi, wawancara, dan foto etnografi menghasilkan kebenaran dalam hasil penelitian[4].

Salah satu teknik yang digunakan untuk mendapatkan data dokumentasi riset etnografi adalah dengan antropologi visual. Antropologi visual dilakukan dengan cara memotret objek penelitian yang dilakukan oleh peneliti. Melalui antropologi visual dapat diketahui perilaku, sikap, dan preferensi dari target. Kekurangan dari teknik adalah subjek penelitian yang bisa saja tidak bertindak sebenarnya karena merasa dalam pengawasan[4].

\section{2) Depth Interview}

Kegiatan ini dilakukan untuk menggali informasi serta menguatkan permasalahan yang di dapat oleh peneliti dari data sekunder sebelumnya mengenai batik gedog Tuban. Depth interview dilakukan kepada narasumber terkait:

\section{- $\quad$ Pengrajin batik gedog}

Wawancara bertujuan untuk mengetahui kondisi batik gedog saat ini, diantaranya motif-motif yang masih masih populer dan banyak di produksi, serta motif yang kurang dikenali dan diminati. Selain itu proses pembuatan batik gedog dari awal hingga akhir.

Hasil Wawancara:

- Motif di masa dulu lebih detail dan teliti dari masa sekarang.

- Lebih banyak batik yang diproduksi menggunakan kain mori.

- Masyarakat dahulu menggunakan Batik Gedog untuk dipakai dan diwariskan, bukan untuk dijual.

- Pengrajin melakukan inovasi dari motif maupun produk supaya pelanggan tidak jenuh.

- Dinas Perindustrian dan Perdagangan Kabupaten Tuban

Wawancara bertujuan untuk mengetahui usaha pemerintah dalam pelestarian dan perkembangan Batik Gedog Tuban serta informasi mengenai Tuban secara umum, serta data terkait Batik Gedog yang sudah dipatenkan.

Hasil wawancara:

- Pemerintah mengadakan lomba cipta motif supaya masyarakat semangat dalam membuat batik.

- Pemerintah menargetkan minimal satu kali dalam setahun untuk mengikutkan Batik Gedog dalam pameran skala nasional.

- Belum ada pendataan motif Batik Gedog lama.

- Kolektor Batik Gedog

Wawancara bertujuan untuk mengetahui positioning Batik Gedog dibandingkan dengan batik-batik lain serta pandangan Batik Gedog dari orang yang mengoleksi batik.

Hasil wawancara:

- Ada banyak sekali motif dari batik gedog. Namun secara garis besar di bagi menjadi dua macam motif, yakni geometris dan non-geometris. Motif geometris terbagi menjadi dua yakni motif yang terinspirasi dari motif tenun gedog dan motif ceplok. Sedangkan motif non-geometris adalah motif bebas yang polanya dibuat secara bebas (tanpa keteraturan).

- Menurut narasumber motif Batik Gedog yang sudah punah dapat diproduksi kembali apabila terdapat pendokumentasian motif yang baik.

\section{KONSEP DESAIN}

\section{A. Konsep Desain}

Konsep perancangan buku visual ini di tentukan berdasarkan hasil dari desain partisipatif, depth interview dan observasi yang telah dilakukan. Big idea yang menjadi judul perancangan ini adalah "Warna Kehidupan dalam Batik Gedog”. Judul 'warna kehidupan' dapat memiliki dua makna, yang pertama yaitu kehidupan yang berwarna karena menggunakan Batik Gedog, yang kedua yaitu warna dari kain Batik Gedog itu sendiri. Judul ini di angkat karena warna dari Batik Gedog tidak hanya indah secara estetika namun terdapat makna pada warna yang di gunakan yaitu sesuai 

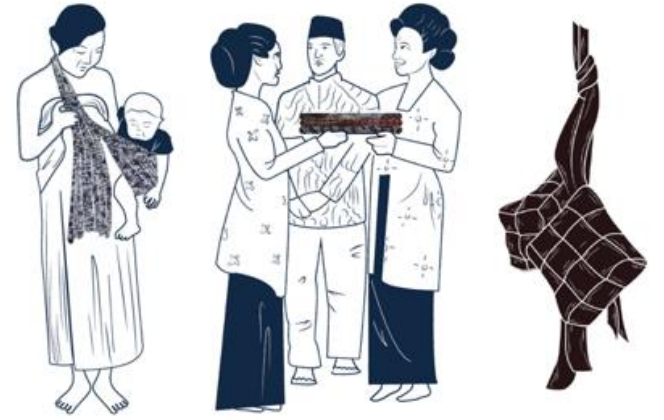

Gambar 8. Ilustrasi pada buku.
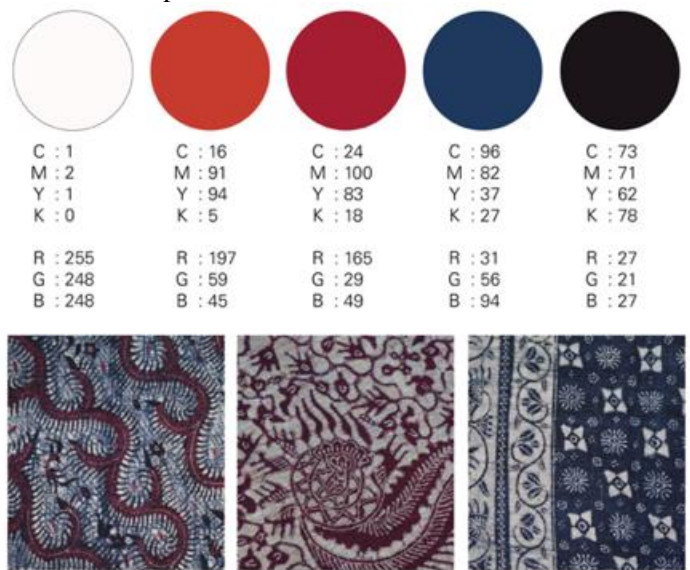

Gambar 9. Palet warna buku.

Laila Medium
ABCDEFGHIJKLMN
OPQRSTUVWXYZ
abcdefghijkImn
opqrstuvwxyz
1234567890

Univers LT Std ABCDEFGHIJKLMN OPQRSTUVWXYZ abcdefghijkImn opqrstuvwxyz 1234567890

Gambar 10. Huruf yang digunakan pada buku.
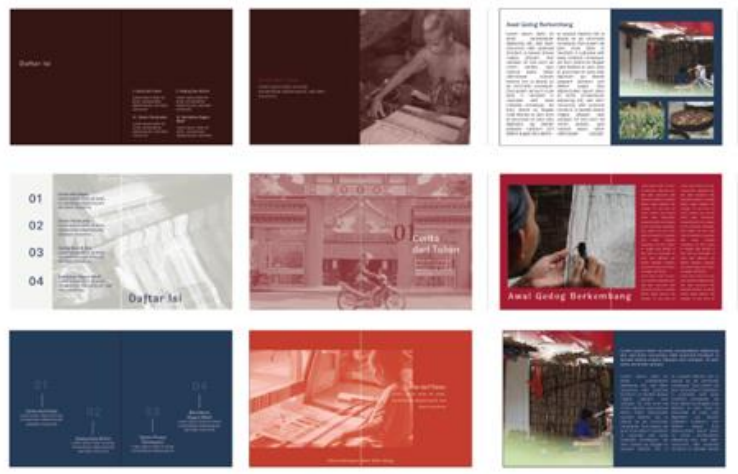

Gambar 11. Altetnatif desain halaman-halam buku.
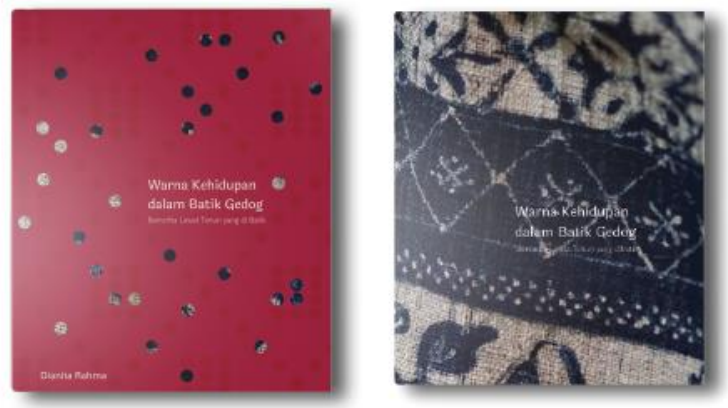

Gambar 12. Sampul buku dan cover buku bagian dalam.

dengan kosmologi kehidupan yang berkembang di masyarakat.

\section{B. Sistematika Buku}

Sistematika kerangka buku pada penelitian ini dapat dilihat pada Gambar 3.

\section{Gaya Bahasa}

Narasi adalah salah satu elemen utama dalam konten buku ini. Dalam buku visual ini teks yang ditampilkan memiliki perbandingan 1:1 dengan elemen visual pada buku. Jenis narasi yang digunakan dalam buku ini adalah teks deskriptif untuk menjelaskan konten buku dengan detail sehingga pembaca bisa memahami konten yang ada, diantaranya adalah proses pembuatan serta penjelasan mengenai sebuah motif. Teks disampaikan menggunakan gaya bahasa tulisan formal yang terikat pada unsur tata bahasa, ejaan, serta kosa kata bahasa Indonesia.

\section{Dimensi Buku \& Desain Grid}

"Warna Kehidupan dalam Batik Gedog" akan dibuat dalam dimensi $20 \mathrm{~cm}$ x $24 \mathrm{~cm}$ x $2 \mathrm{~cm}$. Dimensi buku ini mengacu pada buku yang beredar di pasaran. Selain itu, ukuran yang dipilih akan lebih efisien pada proses cetak karena tidak banyak area yang terbuang.

Layout buku menggunakan grid dua kolom yang fleksibel untuk diisi teks maupun visual. Grid ini dapat membuat isi buku terlihat penuh tanpa berlebihan seperti pada Gambar 4.

Margin buku:

- Margin atas $\quad: 15 \mathrm{~mm}$

- Margin bawah : : $15 \mathrm{~mm}$

- Margin luar $\quad: 15 \mathrm{~mm}$

- Margin dalam $: 16,5 \mathrm{~mm}$

- Gutter : :9 mm

- Kolom :2

\section{E. Fotografi}

Dalam sebuah buku visual, elemen fotografi merupakan elemen yang penting karena jumlahnya yang setara dengan teks. Dalam buku visual ini visual memiliki perbandingan 1:1 karena setiap materi teks yang ada pada buku akan mendapatkan penjelasan dalam bentuk visual. Fotografi akan digunakan secara maksimal untuk dokumentasi yang dapat ditemukan langsung oleh peneliti, diantaranya yaitu motifmotif kain batik, foto lanskap daerah, dan proses pembuatan tenun dan batik.

Hasil foto terbagi dalam beberapa kategori yaitu foto still life yang menunjukkan bentuk dari alat dan bahan proses membatik. Foto documentary untuk mengabadikan proses saat pembatik dan penenun bekerja. Foto table top untuk mendapatkan foto kain batik secara menyeluruh, foto macro untuk mendapatkan foto detail tekstur kain, dan foto lanskap untuk menunjukkan kondisi desa Kerek saat ini dapat dilihat pada Gambar $5-7$.

\section{F. Ilustrasi}

Ilustrasi merupakan media pendukung untuk penggambaran visual yang tidak bisa didapatkan melalui fotografi karena objek yang dicari sulit / tidak bisa didapatkan. Selain itu ilustasi merupakan variasi pada desain buku. Ilustrasi menggunakan gaya outline mengesankan simplifikasi dengan hanya satu warna dan pada bagian batik menggunakan hasil fotografi kain. Motif kain yang ditampilkan dalam ilustrasi sesuai dengan yang digunakan dalam kebutuhan aslinya seperti pada Gambar 8. 


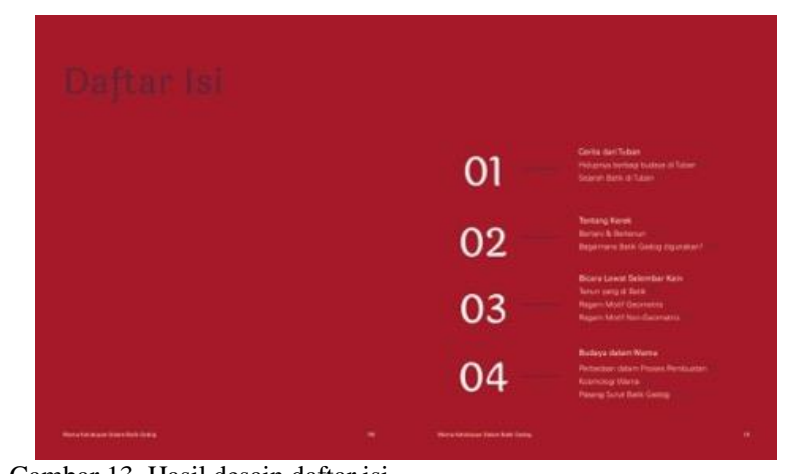

Gambar 13. Hasil desain daftar isi.
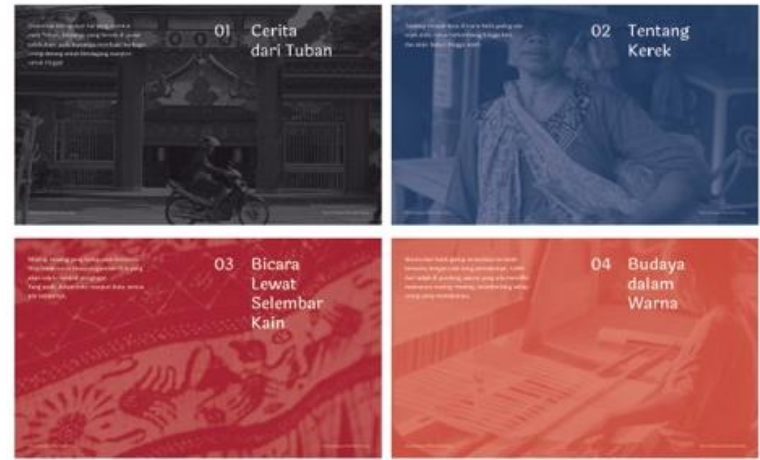

Gambar 14. Hasil desain halaman sub-bab.

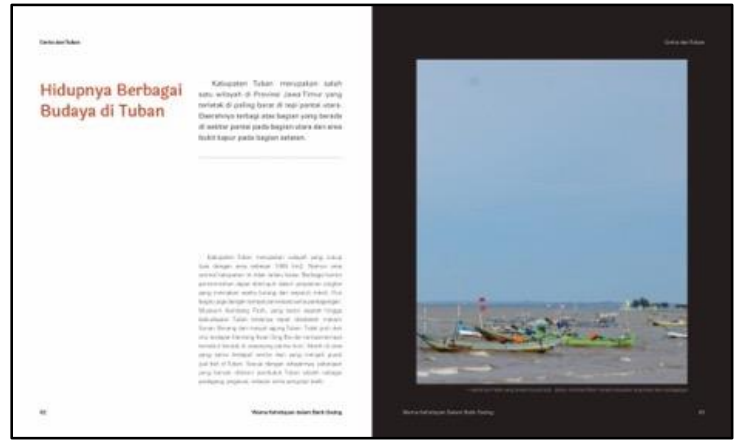

Gambar 15. Hasil desain halaman awal bab.

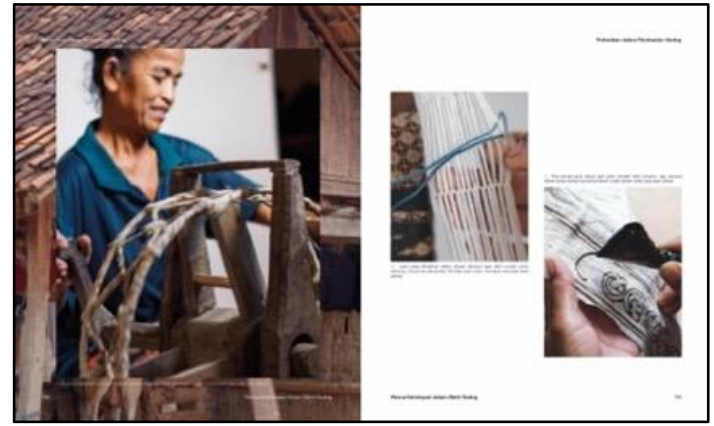

Gambar 16. Hasil desain halaman foto.

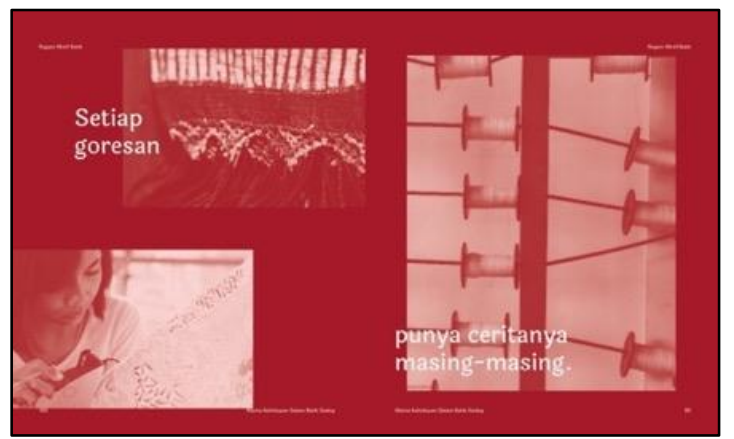

Gambar 17. Hasil desain halaman foto dengan quote.

\section{G. Warna}

Palet warna buku visual ini disesuaikan dengan warna khas batik gedog. Penulis menampilkan biru sebagai warna yang lebih dominan karena merupakan warna khas batik gedog dan berbeda dari batik daerah lain. Menurut kosmologi warna perpaduan biru dan merah digunakan ketika seseorang telah dewasa dan menikah[5]. Warna biru menjadi warna utama dan lebih dominan pada buku visual ini karena menjadi ciri khas dan berbeda dari batik daerah lain. Warna putih merupakan warna pendukung sekaligus penyeimbang dalam palet warna seperti pada Gambar 9.

\section{H. Tipografi}

Buku visual ini menggunakan dua macam font untuk kebutuhan yang berbeda pada buku. Font sans serif merupakan font utama yang penggunaanya paling mendominasi dalam buku. Font Univers dipilih karena memiliki tingkat keterbacaan yang baik yang digunakan untuk judul teks, isi teks, dan caption pada buku. Font ini digunakan dalam dua variasi yaitu Univers 45 Light dan Univers 55 Roman. Isi teks menggunakan ukuran 9pt.

Sedangkan untuk elemen teks yang penting digunakan font Laila agar terlihat kontras dan bagian isi buku. Font ini digunakan untuk judul buku, judul sub-bab buku, serta kutipan. Font Laila digunakan dua macam yaitu Laila medium dan Laila regular. Judul sub-bab buku menggunakan Laila medium ukuran 50pt sedangkan judul paragraf menggunakan ukuran 25pt. Untuk kutipan pada buku menggunakan Laila regular ukuran 16pt supaya berbeda dari judul utama seperti pada Gambar 10.

\section{IMPLEMENTASI DESAIN}

\section{A. Proses Desain}

Penulis membuat masing-masing lima alternatif desain untuk halaman-halaman buku seperti daftar isi, halaman subbab, serta halaman isi. Alternatif desain di buat sesuai kaidah layout yang telah ditentukan sebelumnya seperti pada Gambar 11.

\section{B. Cover Buku}

Sampul terdiri dari dua bagian yaitu selimut buku dan hard cover, dengan selimut buku yang menggunakan teknik cutting laser. Tujuan dari penggunaan selimut buku adalah untuk menunjukkan dua jenis batik dalam cover buku yaitu batik motif geometris pada selimut serta batik non geometris pada bagian dalam. Motif geometris yang dipilih pada sampul adalah krompol yang memiliki makna 'berkumpul'seperti pada Gambar 12.

\section{Front Matter}

Merupakan bagian pengantar yang berisi informasi dari isi buku. Diantara yang merupakan front matter adalah daftar isi, pengantar, serta informasi penerbitan buku seperti pada Gambar 13.

\section{Pembabakan Buku}

Pembabakan bab berguna untuk memisahkan antara satu bab dengan bab lain dengan topik yang berbeda Dengan 


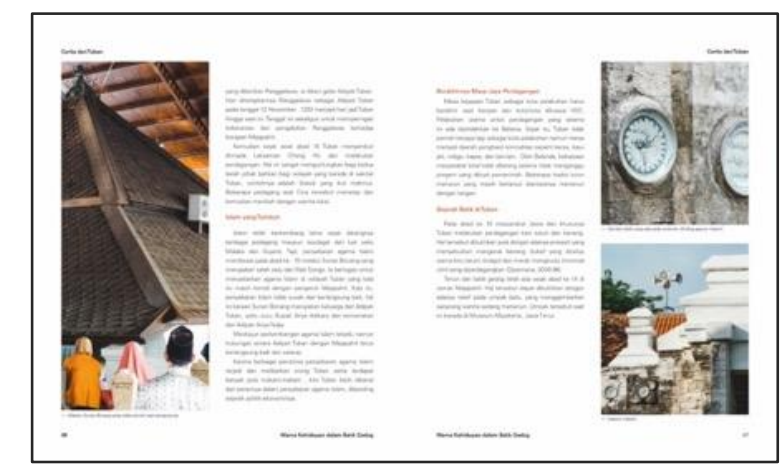

Gambar 18. Hasil desain BAB 1.

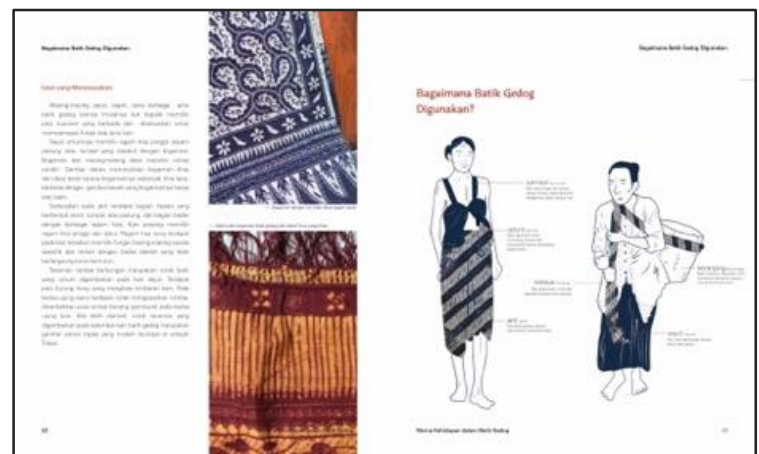

Gambar 19. Hasil desain BAB 2.
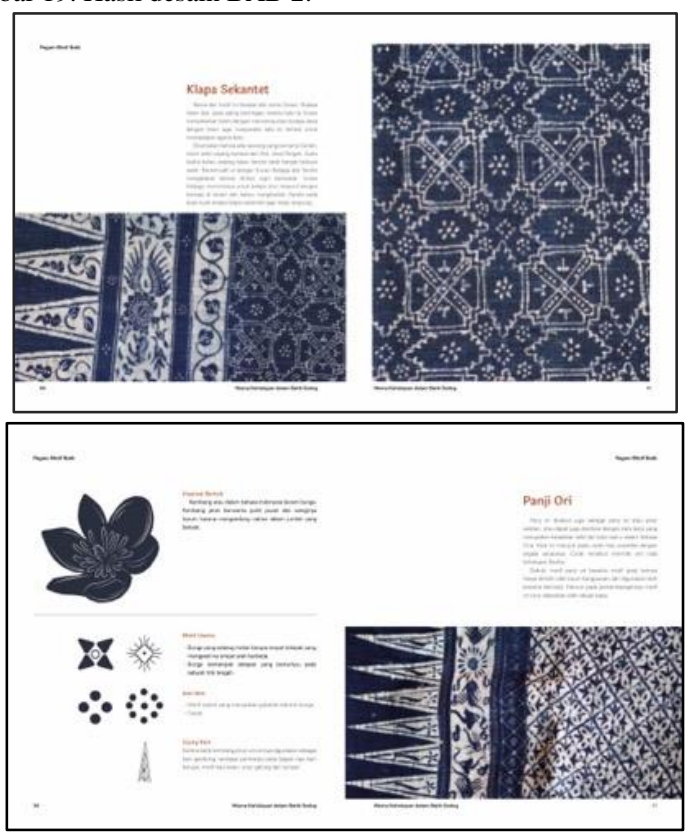

Gambar 20. Hasil desain BAB 3.

memisahkan bab pembaca dapat mengetahui konten apa yang ingin diketahui lebih lanjut. Buku ini dibagi menjadi 4 bab, dengan pembagian warna bab yang disesuaikan dengan warna dari palet warna yang telah ditentukan sebelumnya dapat dilihat pada Gambar 14.

\section{E. Isi Buku}

Terdapat layout buku yang sudah menjadi aturan sehingga penggunaannya berulang pada tiap-tiap bab, serta terdapat layout khas yang hanya ditemui pada bab tertentu. Dengan layout dasar yang menggunakan grid dua kolom. Layout pada tiap halaman awal bab adalah layout yang sudah menjadi aturan dalam buku dapat dilihat pada Gambar $15-17$.

\section{1) $B A B 1$}

Bab satu membahas sejarah kota Tuban. Penjelasan mengenai Tuban perlu ada dalam buku karena sejarah
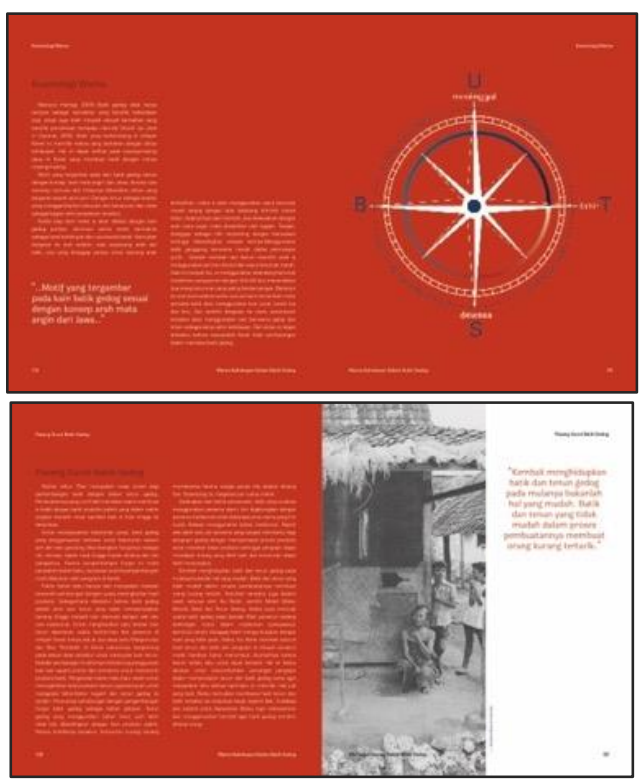

Gambar 21. Hasil desain BAB 4.

kabupaten ini memiliki kaitan dengan Batik Gedog karena motif yang ada memiliki nilai budaya dibaliknya. Terdapat sejarah mengenai perkembangan budaya Cina yang meliputi agama yang dibawa, serta agama Islam yang besar hingga saat ini. Bab ini berisikan cerita serta foto objek-objek di kabupaten Tuban dapat dilihat pada Gambar 18.

2) $B A B 2$

Bab ini berisi hal yang berkaitan dengan kecamatan Kerek sebagai wilayah yang memproduksi Batik Gedog. Di wilayah ini terdapat lima desa yang aktif membuat Batik Gedog.Di Kerek umumnya terdapat dua jenis batik yang di produksi. Selain itu dijelaskan bagaimana Batik Gedog digunakan pada masa lalu yang ditampilkan melalui ilustrasi dapat dilihat pada Gambar 19.

3) $B A B 3$

Bab ini merupakan bab dengan isi konten utama, membahas motif dan makna dari selembar Batik Gedog. Terdapat 22 motif yang dibahas dalam buku ini. Bahasan dari motif meliputi informasi umum mengenai batik, inspirasi bentuk, sejarah dari batik, dan penjabaran ornamen yang ada pada selembar batik dapat dilihat pada Gambar 20.

4) $B A B 4$

Penggunaan warna dalam Batik Gedog yang digunakan memiliki aturan tertentu, diantaranya anak-anak yang menggunakan batik putihan hingga pada usia lanjut yang menggunakan batik warna biru gelap kehitaman. Warna juga menjadi identitas seseorang ketika berada di tempat umum. Pewarnaan Batik Gedog tidak hanya dilakukan sesuai selera pembatik, namun memiliki aturan tertentu. Oleh karena itu bab ini akan membahas filosofi dibalik pewarnaan batik Selain itu sebagai konklusi, dibahas perkembangan batik gedog hingga saat ini. Terdapat foto detail dari motif batik beserta ilustrasi peta wilayah Kerek dapat dilihat pada Gambar 21.

\section{KESIMPULAN DAN SARAN}

\section{A. Kesimpulan}

Perancangan buku visual Batik Gedog berfungsi sebagai media untuk mendokumentasikan motif batik Tuban yang mampu menampilkan 22 ragam motif beserta penjabaran 
masing-masing dan makna dari motif tersebut. Berdasarkan depth interview yang dilakukan kepada pengrajin dan kolektor batik gedog, narasumber setuju bahwa dengan mendokumentasikan motif yang baik bermanfaat agar motif tidak hilang dan menjadi arsip agar motif dapat dibuat kembali. Kemudian, elemen visual berupa fotografi table top yang menampilkan keseluruhan motif kain digunakan untuk menunjukkan contoh Batik Gedog. Terakhir, selain melalui fotografi, elemen desain berupa ilustrasi berfungsi untuk menggambarkan kegiatan maupun objek yang tidak bisa didapatkan hasil fotografinya, sekaligus menambah variasi konten visual pada buku.

\section{B. Saran}

Dari segi penulisan buku ini perlu dibenahi kembali penggunaan kata sambung, huruf kapital, serta penggunaan kalimat yang tidak efektif. Kedua, setiap motif yang dijabarkan dapat digali lebih dalam aspek budaya serta filosofinya. Terakhir, pembabakan dan materi yang ada dalam buku sebaiknya dibuat sesuai kebutuhan konten dari target audiens agar isi yang didapatkan sesuai dengan kebutuhan audiens.

\section{DAFTAR PUSTAKA}

[1] B. Bramantijo, T. Priyoleksono, A. Sinaga, H. Prajitno, and T Solehkhudin, "Inventarisasi Motif Tradisional Batik Gedhok Tuban Sebagai Upaya Pelestarian Khasanah Tradisi Jawa Timur," Surabaya, Indonesia, 2014.

[2] B. Tondreau, Layout Essentials: 100 Design Principles for Using Grids (Design Essentials). Beverly Hills, California: Rockport Publishers, 2011.

[3] S. Rustan, Layout Dasar dan Penerapannya. Gramedia Pustaka Utama, 2008.

[4] J. V. O'Grady and K. O'Grady, A Designer's Research Manual: Succeed in Design by Knowing Your Clients and What They Really Need (Design Field Guide). Beverly Hills, California: Rockport Publishers, 2009

[5] F. Ciptandi, A. Sachari, and A. Haldani, "Fungsi dan nilai pada kain batik tulis gedhog khas masyarakat di kecamatan kerek, kabupaten tuban, jawa timur," Panggung, vol. 26, no. 3, pp. 261-271, 2016. 